\title{
A Proteção do Meio Ambiente no Peru e o Capítulo dos Investimentos no Acordo de Livre Comércio com os Estados Unidos da América
}

\author{
Lira Luz Benites Lázaro(*)
}

\begin{abstract}
Resumo: A assinatura do Tratado de Livre Comércio com os Estados Unidos da América tem levado o governo peruano a realizar ações para sua implementação, visando a promoção comercial dos recursos naturais, que reformulam o sistema de distribuição de terra, da floresta, dos direitos das comunidades campesinas e dos povos indígenas, o qual tem suscitado conflitos sociais que na sua maioria são por questões ambientais. Neste artigo, descrevemos as implicações ambientais do Capítulo de Investimento do Tratado de Livre Comércio entre Peru e os Estados Unidos, cujos artigos são imperativos na proteção e promoção dos interesses dos investidores diretos estrangeiros frente ao frágil Capítulo Ambiental de proteção ao meio ambiente.
\end{abstract}

Palavras-chaves: Proteção ao Meio Ambiente, Capítulo de Investimento, Tratado de Livre Comércio.

\begin{abstract}
The signing of the Free Trade Agreement with the United States has led the Peruvian government to take measures for their implementation in order to facilitate the promotion of the trade of the natural resources, which reformulate the system of distribution of the land, the forests, the rights of the peasant communities and the indigenous people, which has caused social conflicts that are mostly due for environmental reasons. This paper describes the environment implications of the investment Chapter of the Free Trade Agreement between Peru and the United States, whose articles are imperative in protecting and promoting the interests of foreign direct investors against the fragile Environment Chapter.
\end{abstract}

Keywords: Environmental Protection, Investment Chapter, Free Trade Agreement.

(*) Advogada, Graduada na Universidade Los Angeles de Chimbote - Peru, Mestre e Doutoranda no Programa de Pós-Graduação em Integração da América Latina. E-mail: <lbenites@usp.br>. Recebido em 27.4.2010 e aceito em 23.9.2010. 


\section{INTRODUÇÃO}

O Tratado de Livre Comércio entre o Peru e os Estados Unidos de América (TLC Peru-EUA) foi assinado em 8 de dezembro de 2005 em Washington pelos presidentes George W. Bush e Alan Garcia. Aprovado pelo Congresso peruano em abril de 2006 e, tendo entrado em vigor em fevereiro de 2009, este acordo comercial inclui temas importantes relativos a investimentos, compras governamentais, telecomunicações, comércio eletrônico, proteção dos direitos de propriedade intelectual, trabalhistas e ambientais.

O interesse do Peru em assinar um TLC com os Estados Unidos de América (EUA) veio como uma resposta ao término em dezembro de 2006 do ATPDEA (Andean Trade Promotion Drug Erradication Act, pelas suas siglas no inglês). O objetivo principal do ATPDEA era promover a diversificação das exportações e oferecer alternativas econômicas diferentes para diminuir a produção de culturas utilizadas para a produção e comércio ilícito de drogas na região andina.

O Sistema Unilateral de Preferências Comerciais - ATPA (Andean Trade Preferences $A c t)^{(1)}$, foi outorgado pelos Estados Unidos aos países andinos, entre eles o Peru, pela primeira vez no ano de 1991 e expirou em dezembro de 2001. No ano de 2002, o Congresso dos Estados Unidos aprovou um novo texto renovando e ampliando os benefícios do ATPA, que passaria ser chamada "Lei de Promoção Comercial Andina e de Erradicação de Drogas" ou ATPDEA. Além dos produtos contidos no ATPA, a nova Lei ATPDEA incluiu produtos como confecções, petróleo e seus derivados, calçado e manufaturas de couro.

Para os setores peruanos que promoviam o TLC Peru-EU, este sistema de Preferências Unilaterais Comerciais, além de ter restrições de tempo, também apresentava limitações para promover investimentos de longo prazo que permitissem um crescimento continuado das exportações (PERU, 2005). Precisamente, uma das motivações que o TLC procura é assegurar um acesso preferencial (com isenção tarifária) de caráter permanente para todos os produtos que conformam a oferta exportável peruana. Além disso, segundo Morón et al. (2005), o Peru já experimentava os benefícios que traz uma tarifa de acesso livre para um mercado importante como os EUA, com a entrada em vigor do ATPA e, posteriormente, o ATPDEA.

Segundo a informação do Ministério de Comércio Exterior do Peru, o principal parceiro sociocomercial peruano são os Estados Unidos da América e a assinatura do TLC constitui um elemento central da estratégia de integração econômica e comercial ao mundo, uma vez que representa a consolidação de um acesso preferencial ao principal parceiro comercial, que concentra 29\% das exportações e $20 \%$ das importações (PERU, $2005)$.

(1) O objeto do ATPA é incentivar as exportações mediante o estabelecimento de um mercado preferencial que gere fontes de trabalho alternativas que ajudem a substituição do cultivo da folha de coca e a redução do tráfico ilícito de drogas, mediante este sistema os Estados Unidos ofereceu ingressos livres de tarifas alfandegárias a 5,500 produtos. Informação disponível em: <http://www.mincetur.gob.pe/comercio/otros/atpdea/ley_atpa_atpdea/.htm/> Acesso em: 30.10.2009. 
Das motivações, importância e objetivos que levaram a assinatura do tratado de livre comércio (TLC), fica claramente evidenciado que para o Peru os aspectos comerciais e econômicos foram mais relevantes que ter propriamente uma preocupação para o meio ambiente ou com o desenvolvimento sustentável das comunidades campesinas, os povos indígenas ou a população peruana em geral.

O presente artigo tem por objetivo descrever as implicações ambientais do Capítulo dos Investimentos do Tratado de Livre Comércio assinado entre Peru e os Estados Unidos, cujos artigos são imperativos na proteção e promoção dos interesses dos investidores diretos estrangeiros frente ao frágil Capítulo Ambiental de proteção ao meio ambiente e as deficiências na legislação ambiental no Peru, e expor a nossa preocupação de como será o tratamento que o Peru dará aos assuntos ambientais depois da assinatura do Tratado de Livre Comércio com os EUA.

\section{O capítulo do investimento no Tratado de Livre Comércio do Peru e os ESTADOS UNIDOS: OS PRECEDENTES DE DISPUTA ENTRE O INVESTIDOR-ESTADO ENVOLVENDO ASSUNTOS AMBIENTAIS}

No ano de 1950 quando foi frustrada a existência da Organização Internacional do Comércio, que continha um conjunto abrangente de regras multilaterais de investimento, os países receptores de investimentos e os países ou empresas investidores procuraram proteger seus interesses respectivos mediante Acordos de Investimentos Bilaterais, Regionais e Multilaterais. Na metade da década de 1990, na Rodada Uruguai foram introduzidas regras de investimento na dimensão do comércio multilateral, com implicações para o investimento estrangeiro (OECD, 2004). Após a Rodada Uruguai, no âmbito da Organização Mundial do Comércio (OMC), os investimentos internacionais se tornaram uma questão relevante no núcleo do sistema multilateral de comércio.

Na América Latina, o Tratado de Livre Comércio de América do Norte (NAFTA pela suas siglas no inglês) assentaram precedentes, para os acordos de livre comércio em todos os níveis. Em especial o seu capítulo XI tem sido uma fonte de preocupação, para toda a região, por abordar assuntos referidos à promoção do Investimento Estrangeiro Direto (IED) que concedem direitos e poderes sem precedentes às empresas transnacionais (BID, 2005). Desde então, todos os TLCs, firmados com os Estados Unidos estão incorporado capítulos específicos sobre os investimentos.

Segundo os promotores dos TLCs, nas negociações sobre investimentos, procura-se promover a entrada de capitais em condições que dão estabilidade e segurança aos investidores, sem se expor a um tratamento discriminatório. A extensiva proteção e o sistema privado de resolução de litígios são necessários para proteger os investidores contra a expropriação da propriedade privada pelo Estado receptor de investimentos (IISD, 1999; PUBLIC CITIZEN, 2005).

No Capítulo de Investimentos do TLC Peru-EUA, existem temas inquietantes, e com precedentes em outros TLCs desfavoráveis à proteção do meio ambiente como: 
obrigações do Tratamento Nacional (art. 10.3), obrigações para um Nível Mínimo de Tratamento (art. 10.5), Proteção de Expropriação e Expropriação Indireta (art. 10.7), Proibição de Requisitos de Desempenho (art. 10.9).

No artigo das definições gerais do Capítulo dos Investimentos, tem-se enfatizado a inclusão dos recursos naturais e os investimentos, como elementos centrais do acordo Estado-investidor. Segundo Mendoza (2008), este fato não deve surpreender se considerarmos que muitos dos mais importantes investimentos no Peru por empresas estadunidenses têm sido em setores dedicados à extração e aproveitamento dos recursos naturais.

\section{O Tratamento Nacional e o caso Pope \& Talbot}

$\mathrm{O}$ art. 10.3 sobre o Tratamento Nacional obriga as partes de cada país signatário de um acordo comercial a "conceder aos investidores da outra um tratamento não menos favorável que o que concede, em circunstâncias similares, a seus próprios investidores”. Princípio que foi negociado e aprovado pelo Peru com relativa facilidade por estar claramente estabelecido na Constituição peruana ${ }^{(2)}$, que consagra a igualdade perante a lei do nacional e do estrangeiro, tanto no que se refere ao tratamento dos seus investimentos, como no que diz respeito aos direitos de propriedade.

Desta forma, o Peru é um dos poucos países onde o conceito do Tratamento Nacional alcançou status constitucional. Torna-se um assunto preocupante porque o Estado peruano não pode desenvolver políticas diferenciadas e autônomas de fortalecimento sustentável em áreas críticas, e estratégicas. Ou não pode estabelecer obrigações e responsabilidades do empresário para garantir os investimentos sustentáveis, incluindo a avaliação e sistemas de gestão ambiental; assim como o Estado peruano não pode garantir que os passivos ambientais dos investidores estrangeiros sejam razoavelmente atendidos e promover a capacidade pública para proteger o meio ambiente.

Os antecedentes do uso deste artigo a favor dos investidores estrangeiros, como o caso do Pope \& Talbot, mostra-nos que, para o Peru, é legalmente inviável aplicar medidas ambientais contra os interesses dos investidores estrangeiros.

O caso do Pope \& Talbot, empresa madeireira dos Estados Unidos, impugna a execução canadense da Ata de Controle de Exportação, no que diz respeito à fixação de cotas de exportação de madeiras-brandas como medida ao excesso de exportação e de desmatamento. Essa impugnação foi a quatro províncias canadenses (Columbia Britânica, Alberta, Ontário e Quebec). A empresa Pope \& Talbot, estabelecida na Columbia Britânica, reclama que a fixação de cotas e taxas não cumpre com o tratamento nacional do que é concedida a outras empresas nacionais em outros estados. A Pope \& Talbot alegava trato menos favorável, por sentir os efeitos de uma regulamentação federal de execução

(2) Art. 63. La inversión nacional y la extranjera se sujetan a las mismas condiciones. La producción de bienes y servicios y el comercio exterior son libres. Si otro país o países adoptan medidas proteccionistas o discriminatorias que perjudiquen el interés nacional, el Estado puede, en defensa de éste, adoptar medidas análogas. Constituição do Peru de 1993. 
de cotas de exportação de madeira mais fortemente no estado onde operava do que em outros estados do Canadá que não estavam sujeitas às cotas de madeira-branda (IISD, 1999). Finalmente, o tribunal de solução de disputas pronunciou-se contra o Canadá, sustentando que a empresa tinha sofrido violações da garantia de tratamento nacional estabelecida no NAFTA.

\section{O nível mínimo de tratamento: os casos Metalclad e S. D. Myers}

A obrigação de um Nível Mínimo de Tratamento do art. 10.5 diz que cada parte concederá aos investimentos um tratamento de acordo com o direito internacional consuetudinário, incluindo um trato justo e equânime como proteção e segurança total. Entretanto, o enunciado deste artigo não fica claro, respeito ao qual seria o padrão mínimo de tratamento que deveria cumprir o governo.

Em geral, houve alguns conflitos em outros TLCs, com relação à violação do princípio do Tratamento Mínimo. Um dos mais conhecidos foi da empresa dos Estados Unidos Metalclad Corporation que alegou este princípio contra o governo mexicano porque o município de Guadalcazar tentou definir as normas ambientais e não autorizar a instalação de confinamento de resíduos perigosos. O Tribunal especial do Centro Internacional para Acerto de Disputas sobre Investimentos (CIADI) (3) $^{(3)}$ estabeleceu que as normas ambientais eram barreiras inaceitáveis e sentenciou que o governo do México deveria pagar uma indenização no valor de US\$16.685.000 a favor de Metalclad.

O caso S. D. Myers, empresa norte-americana de tratamento de resíduos tóxicos, impugnou uma proibição imposta pelo Canadá contra as exportações de policlorobifenilos (PCB), em conformidade com um acordo ambiental multilateral sobre comércio de resíduos tóxicos (Convenção de Basileia). No entanto, esse tribunal determinou que a ação do Canadá era ilegal à luz do nível de trato mínimo disposto no NAFTA e decidiu que a forma pela qual o Canadá havia tentado alcançar o seu objetivo ambiental não foi a que teria os efeitos menos restritivos sobre o comércio ${ }^{(4)}$.

\section{A EXPROPRIAÇÃo E EXPROPRIAÇÃo INDIRETA: CASOS EMPRESA ETHYL, GLAMIS GoLd E LUCHETTI}

O conceito de expropriação do art. 10.7, segundo o espírito tradicional da legislação internacional, sobre os mecanismos de expropriação, consiste em proteger a propriedade

(3) O CIADI opera sob os auspícios do Banco Mundial, começou a funcionar em 1966 como o braço executivo de um tratado internacional conhecido como o Convênio sobre o Acerto de Diferenças em torno de Investimentos entre Estados e Nacionais de Outros Estados. Esse convênio atribuiu ao CIADI o papel de administrar o sistema de arbitragem completamente novo que ele criou para solucionar controvérsias entre países e investidores privados estrangeiros. Em termos gerais, o objetivo desse novo sistema era solucionar controvérsias contratuais específicas entre governos e empresas contratantes - e não questões delicadas de política pública.

(4) Para mais informação sobre os conflitos surgidos Investidor-Estado ver: International Institute for Sustainable Development - IISD. Una guía sobre el controvertido capítulo del TLCAN referente a los derechos de los inversionistas, 2001 . 
privada dos estrangeiros contra as medidas ostensivas de expropriação ou nacionalização por parte do Estado anfitrião dos investimentos. No TLC Peru-EUA, foi introduzido o termo “expropriação indireta”. Segundo o art. 10.7.1, a expropriação indireta ocorre quando uma medida aplicada pelo governo tem um efeito equivalente a uma expropriação direta, sem transferência formal de propriedade ou direitos de domínio. Esta interpretação dá aos ganhos potenciais futuros a mesma categoria outorgada aos investimentos efetivos (ECHAVE, 2006).

No âmbito do NAFTA, existem antecedentes que governos signatários de tratados de livre comércio foram obrigados a compensar as empresas estrangeiras pelas perdas dos seus lucros futuros, como consequência da aplicação das suas legislações ambientais nacionais. Como por exemplo, o caso da Ethyl empresa de produtos químicos dos Estados Unidos que impugnou uma regulação ambiental e de saúde pública do governo canadense, que restringia a utilização de um aditivo (MMT - Methylcyclopentadienyl manganese tricarbonyl) de gasolina que contém manganês, e cuja inalação provoca incapacidade neurológica e sintomas semelhantes aos do Parkinson.

A empresa Ethyl considerou que a proibição do governo do Canadá equivalia a uma expropriação indireta e reclamou uma indenização de US\$250 milhões de dólares. O caso foi resolvido extrajudicialmente a favor de Ethyl com US\$ 13 milhões de indenização.

A empresa mineradora canadense Glamis Gold demandou ao governo dos EUA porque o estado da Califórnia aprovou uma série de requisitos que visavam minimizar o impacto ambiental e social das minas a céu aberto no seu território. Para a Glamis Gold, a imposição da nova lei prejudicava os seus investimentos e suas expectativas de lucro. Assim começou sua demanda contra o governo dos EUA sobre a proteção do Capítulo XI do NAFTA, exigindo uma indenização de US\$ 50 milhões.

$\mathrm{Na}$ esfera do NAFTA, as demandas do investidor-Estado apresentadas tiveram pouco a ver com a expropriação pelo governo de propriedades dos investidores. Em vez disso, essas ações impugnaram leis ambientais, regulamentos, decisões judiciais e outras ações internas do governo receptor dos investidores estrangeiros.

O Estado peruano também foi submetido a um processo injustificado e arriscado, gerado por um investidor estrangeiro envolvido em atos irregulares e cujos objetivos eram ilegítimos; e que unilateralmente fez uso indevido das liberdades e privilégios concedidos em favor dos investimentos estrangeiros, para especular com um processo de arbitragem, que exigia ao Estado peruano tempo e recursos.

O caso Luchetti foi paradigmático para o Peru, precisamente por causa dos elementos anômalo, irregular e questionável que sustentavam a acusação da empresa chilena (MENDOZA, 2008). A empresa Luchetti do ramo de macarrões demandou ante a CIADI ao Peru por supostos danos causados nos seus lucros futuros pelo cancelamento de sua licença para operar uma planta que tinha construído nos arredores da reserva ecológica de "Los Pantanos de Villa” ao sul de Lima.

A justiça peruana tinha sentenciado que a existência da fábrica em uma zona ecológica era inviável e que a licença outorgada à empresa não era válida, tendo sido 
concedido irregularmente, durante a época do governo de Fujimori, e que à empresa não assistia direito algum de exigir uma indenização. Apesar disso, o Estado peruano foi levado a julgamento.

\section{O REQUISITO DE DESEMPENHO: CASO ETHYL}

O art. 10.9 proíbe aos países receptores de investimentos de impor certos tipos de requisitos de desempenho aos investidores como uma condição de entrada e estabelecimento. Entre as exigências estão: de alcançar determinada porcentagem de conteúdo nacional; comprar, utilizar ou outorgar preferências a bens produzidos no território onde estão estabelecidos; e exigências para transferência de certas tecnologias ou conhecimentos exclusivos para o país hospedeiro.

A preocupação aqui é a incerteza de que a medida poderia ser usada contra qualquer resolução que restringisse a importação ou exportação de bens, ou impusesse qualquer cota ou tarifa, que estivesse ou não relacionado com uma empresa determinada, ou como uma condição de investimento. Que, em vários casos, tem sido argumentado, que uma proibição de importação constitui uma exigência de desempenho. No caso da empresa Ethyl, alegou que a proibição de importação de MMT teve o efeito de um requisito de desempenho, porque efetivamente forçou a empresa a produzir o produto no mercado interno em vez de importar. O caso foi resolvido extrajudicialmente a favor do demandante, mantendo assim a incerteza.

Por este artigo, quaisquer iniciativas peruanas para desenvolver no futuro, requisitos de desempenho para os investimentos, estarão apenas determinadas pelos chamados mecanismos voluntários das próprias empresas, que se implementarão por meio de seus códigos de conduta e outros instrumentos de autorregulação expressos em discursos de responsabilidade socioambiental empresarial; caberá à sociedade peruana esperar as boas práticas ambientais, fruto da consciência ambiental das empresas, porque mesmo no capítulo ambiental no art. 18.5 sobre as medidas para melhorar o Desempenho Ambiental, somente se promovem mecanismos flexíveis e voluntários para a proteção do meio ambiente.

O Capítulo sobre investimentos do TLC inclui uma série de disposições que, em vez de incentivar melhores práticas de investimentos, reduz a capacidade do Peru para regular os IEDs e vinculá-los com os objetivos de desenvolvimento nacional (FAIRLIE et al.,2006). Assim, o Peru, ficará impossibilitado de exigir um comportamento responsável aos investidores estrangeiros, e será muito vulnerável de cair em disputas entre investidores e o Estado.

Os precedentes são claros, os interesses das empresas estrangeiras são colocados acima das legislações nacionais de proteção ao meio ambiente e da saúde dos seus habitantes. Os casos como do Metalclad, do Ethyl e o S. D. Myers refletem claramente muitas das piores falhas e os efeitos do regime de arbitragem internacional, que é baseado 
em estruturas destinadas a dar preferência aos interesses privados contra os interesses públicos ou do meio ambiente.

Neste sentido, é evidente que o estabelecimento de acordos-quadro e acordos específicos visa o desenvolvimento gradual de um sistema de "blindagem do investimento" contra eventuais riscos e perdas pela acumulação gradual de garantias e benefícios para os IEDs (MENDOZA, 2008).

Para o Peru, a assinatura do TLC com os EU esteve focada unicamente em destacar o fator econômico, de assegurar um aceso preferencial às exportações de caráter permanente, atrair investimentos, estabelecer regras claras e duradouras para o comércio de bens e serviços. Com razão, Celli (2006) diz que "a tendência é que sejam firmados tratados constitutivos de zona de livre comércio em que se privilegiam mais os aspectos comerciais e econômicos”, que, propriamente ter preocupação para o meio ambiente, ou com o desenvolvimento autônomo e sustentável, com a inclusão de temas e programas que tivessem como beneficiários últimos as populações abrangidas.

\section{O capítulo do meio ambiente no Tratado de Livre Comércio do Peru e os Estados Unidos}

A preocupação ambiental em nível internacional começa no ano de 1972, com a Conferência das Nações Unidas sobre o Ambiente Humano, realizada em Estocolmo, Suécia. A Conferência de Estocolmo levou a criação do Programa das Nações Unidas do Meio Ambiente - PNUMA, principal órgão das Nações Unidas na esfera ambiental.

A Comissão Mundial sobre Meio Ambiente e Desenvolvimento, instituída em 1985, emitiu seu relatório em 1987 Nosso Futuro Comum (conhecido também como "Relatório Brundtland”). Este relatório foi a primeira articulação sistemática do conceito de "desenvolvimento sustentável”(5); tornando-se a base para uma análise aprofundada de todas as atividades internacionais ambientais, pela Conferência das Nações Unidas sobre o Ambiente e o Desenvolvimento (UNCED), como a realizada em 1992 no Rio de Janeiro, Brasil (UNEP, 2004).

Os debates sobre assuntos ambientais na UNCED, que ocorreram em paralelo à Rodada Uruguai (1986-1994), instigaram a discussão de questões ambientais no âmbito do Acordo Geral de Tarifas e Comércio (GATT). E, principalmente, a controvérsia “atum-golfinho” ${ }^{(6)}$ envolvendo o uso de restrições comerciais com propósitos ambientais,

(5) Desenvolvimento sustentável "O desenvolvimento que atende as necessidades do presente sem comprometer a habilidade das gerações futuras de atender suas próprias necessidades” (CMMAD, 1991).

(6) Os Estados Unidos em virtude de sua lei sobre a proteção dos mamíferos marinhos, atendendo ao seu setor de pesca e às reivindicações de organizações ambientalistas, impuseram restrições às importações de atum mexicano, cuja técnica de captura implicasse numa elevada taxa de mortandade acidental de golfinhos. Tais medidas prejudicaram o México que, prontamente, acionou o GATT para a defesa de seus interesses comerciais, os EU e México chegaram a uma solução extrajudicial. A conclusão do GATT foi que as regras não permitem que um país tome ações no sentido de impor suas leis a outro, mesmo para proteger recursos naturais ou animais (ALMEIDA et al., 2004). 
entre os Estados Unidos e o México, surgida em 1991 e estendida ao longo de 1992, foi um catalisador da "reação ambiental" no GATT.

No âmbito dos tratados de livre comércio, o primeiro acordo comercial no qual se discutiu o tema ambiental foi NAFTA. E diante todos os acordos comerciais celebrados pelos Estados Unidos, incluem disposições ambientais no corpo do acordo, seguindo um padrão semelhante. Todos os acordos são acompanhados por um Acordo de Cooperação Ambiental (ECA) (OCDE, 2008).

O TLC Peru-EU contém disposições no corpo do acordo que faz referência ao meio ambiente e proteção ambiental no preâmbulo. Um artigo sobre a Diversidade Biológica, além de incluir um anexo inovador na Gestão do Setor Florestal, reconhecendo as consequências ambientais e econômicas do comércio relacionado com a exploração madeireira ilegal e ao comércio ilegal de animais selvagens (OCDE, 2008).

O Capítulo 18 do Meio Ambiente contém disposições pormenorizadas sobre níveis de proteção (art. 18.1), acordos ambientais (art. 18.2), aplicação das leis ambientais (art. 18.3), regras processuais (art. 18.4), mecanismos para melhorar o desempenho ambiental (art. 18.5), conselho de assuntos ambientais (art. 18.6), oportunidades para a participação do público (art. 18.7), solicitudes sobre assuntos de cumprimento (art. 18.8), registros de fatos e cooperação relacionados (art. 18.9), cooperação ambiental (art. 18.10), diversidade biológica (art. 18.11), consultas ambientais e procedimento do painel (art. 18.12), relação com os acordos ambientais (art. 18.13), definições (art. 18.14), acordos cobertos (Anexo 18.2), gestão do setor florestal (Anexo 18.3.4).

$\mathrm{O}$ art. 18.3 chama especial atenção sobre a aplicação e observância das leis ambientais e dispõe que "uma parte não deixará de aplicar efetivamente sua legislação ambiental, através de um curso de ação, ou inação, sustenido o recorrente, de maneira que afete o comércio entre as partes...” (Literal 1.a). Deste modo, o tema comercial é considerado acima da proteção ao meio ambiente. Assim, a aplicação e a observância das leis ambientais no TLC determinam-se na medida a que se afeta ao comércio entre as partes; somente no caso que a inaplicabilidade das leis ambientais tenha efeito negativo no comércio e nos investimentos entre ambas as partes serão consideradas como una violação a tais leis.

Para Fairlie (et al., 2006), neste artigo, existe um dualismo, uma vez que em alguns casos fala-se de leis ambientais no âmbito do Tratado e em outras da legislação ambiental interna. O primeiro é muito restritivo e só é considerado violado quando afeta o comércio entre as partes. Enquanto o segundo, como é entendido no contexto do TLC, não garante de forma explícita a proteção do meio ambiente, exclusivamente é apresentado como um conjunto de exortações sem força de lei.

$\mathrm{O}$ art. 18.4 promove a adoção de regras de procedimento em caso de violação da legislação ambiental. No entanto, na prática, não garante a aplicação efetiva da legislação ambiental nacional, tendo em vista o disposto no art. 18.2. Nos termos do TLC, apenas violações às leis ambientais que afetam o comércio e os investimentos serão punidos. Além disso, há limitações no estabelecimento e aplicação de sanções por perdas e danos 
contra o meio ambiente, que é de especial importância no caso das indústrias extrativas (FAIRLIE, et al., 2006; BARANDIARÁN, 2008).

Ao contrário do que ocorre com as regras que garantem os direitos dos investidores, que são obrigatórias no âmbito do TLC, a cláusula ambiental é obviamente voluntária. Claramente estabelecido no art. 18.5 sobre as medidas para melhorar o desempenho ambiental, somente se promove ou incentiva a adoção de mecanismos "flexíveis e voluntários" para a proteção do meio ambiente, mas não se fala nada em estabelecer compromissos responsáveis e obrigatórios para a correta gestão ambiental por parte das empresas. Na prática, essa terminologia ambiental não vale nada, como nos exemplificam as disputas na esfera do NAFTA, considerando que os tribunais de arbitragem estabelecidos para julgar controvérsias protegem os direitos dos investidores.

Os representantes democratas da Câmara dos Estados Unidos promoveram a renegociação do capítulo meio ambiente do TLC, cujo Protocolo de Emenda foi acordado em junho de 2007. O Anexo de Gestão do Setor Florestal é parte do Protocolo de Emenda e prevê medidas concretas que as partes, em especial o Peru, terão de cumprir e melhorar para a gestão do setor florestal e a promoção do comércio de produtos madeireiros.

Em dezembro de 2007, mediante a Lei n. 29.157, o Congresso peruano deu plenas faculdades ao governo para legislar questões relativas à implementação do TLC e dar cumprimento aos acordos assumidos na assinatura do tratado de livre comércio, em especial, o Anexo sobre Gestão Florestal, para o qual o governo promulgou noventa e nove Decretos Legislativos, referentes especificamente a assuntos ambientais para facilitar e permitir o aproveitamento dos recursos naturais, além de promover a criação do Ministério do Meio Ambiente ${ }^{(7)}$.

A promulgação dos Decretos Legislativos tem propiciado reformas no sistema jurídico peruano e modificações altamente questionadas, especialmente relacionadas à promoção de atividades extrativas que reformulam o sistema de distribuição de terras, água, bosques, direitos das comunidades campesinas e povos indígenas; e não se consegue um consenso no parlamento, constitui temas de conflito social. Segundo a Defensoria do Povo, no Peru em 2008 existiam 177 conflitos sociais dos quais mais da metade relacionados a questões ambientais ${ }^{(8)}$.

No Peru, muitos dos conflitos e controvérsias entre Estado, sociedade e investidores estrangeiros têm girado em torno a temas relacionados com o controle e distribuição dos ingressos gerados pela exploração dos recursos naturais, pelas consequências da extração destas riquezas naturais, contra a pouca sensibilidade de proteção do meio ambiente pelas multinacionais dedicadas à agricultura de exportação, à pecuária, à atividade de mineração, à derrubada de árvores, e pela diferença entre a visão ocidental e a forma de concepção dos indígenas do meio ambiente.

(7) Em 14 de maio de 2008 publicou-se no diário oficial El Peruano o Decreto Legislativo n. 1.013, mediante o qual aprovou-se a lei de criação, organização e funções do Ministério do Meio Ambiente.

(8) CASTILLO, Laureano del. Decretos legislativos - nuevos focos de conflictos. Disponível em: < http://www.redge.org.pe/ noticias/notas-de-prensa/decretos-legislativos-nuevos-focos-de-conflictos $>$ Acesso em: 10.12.2009. 
A concepção do meio ambiente para os indígenas é mística, sagrada e representa a fonte de vida. O indígena, desde seus antepassados, vive numa inter-relação harmoniosa com o meio ambiente. Diferente da visão ocidental que vê os recursos naturais desde uma perspectiva de produtivismo e de uso comercial. Demonstrando assim, que o problema dos conflitos é social, ambiental e cultural como diz a vice-presidente da Asociación Interétnica de Desarrollo de la Selva Peruana - AIDESEP Daysi Zapata "Esta é uma luta para defender a nossa floresta, para defender nossos recursos naturais, para defender nossa cultura e o território em que vivemos”(9).

O TLC Peru-EUA, desde o início de sua negociação, gerou mobilizações na sociedade peruana em rechaço a sua assinatura pelo governo peruano. E a promulgação dos Decretos Legislativos com o objetivo de implementar o TLC levou a uma grande paralisação que se iniciou em nove de agosto de 2008 e provocou a revogação dos Decretos Legislativos ns. 1.015 e 1.073 relativos à posse de terras nas comunidades campesinas e indígenas, que modificava as características de propriedade da água, terra, da floresta amazônica com o objeto de facilitar a transferência para o investimento privado.

Desde agosto de 2008 até o mês de junho de 2009, aumentaram os conflitos sociais em torno da revogação dos Decretos Legislativos, relacionada a temas ambientais, registrando-se 273 conflitos segundo a Defensora do Povo. Os indígenas da AIDESEP e outros grupos da Amazônia exigiram a revogação dos Decretos Legislativos ns. 1.090, sobre a Lei de Florestas e Fauna Silvestre e 1.064 sobre o aproveitamento de Terras de Uso Agrário.

O conflito mais sangrento e severo ocorreu em 5 de junho de 2009, na província de Bagua, com 34 peruanos mortos. Foi o pior conflito social desde que o presidente Alan García tomou posse em 2006 e que causou a renúncia do cargo de Primeiro Ministro a Yehude Simon.

Depois do confronto do 5 de junho de 2009, Yehude Simon, defendeu a derrogatória dos Decretos Legislativos. Segundo ele, para "evitar que se derrame mais sangue"(10) e chegar a um acordo com os povos indígenas. Em 18 de junho de 2009, o pleno do Congresso da República aprovou a revogação, mais uma vez, dos Decretos Legislativos ns. 1.090 e 1.064, decretos amplamente rechaçados pelas comunidades nativas da selva que originaram o violento protesto na cidade de Bagua.

O presidente Alan Garcia, em um discurso para chamar a uma conciliação social, lembrou que o objetivo dos decretos emitidos há um ano sobre a floresta era proteger a Amazônia da exploração madeireira ilegal, do contrabando de madeira, de plantações ilegais de coca, do tráfico de drogas e de mineração informal, bem como para proteger a depredação e contrabando de espécies animais na Amazônia; além de cumprir com os compromissos assumidos no TLC Peru-EUA. Ele diz "Queríamos trazer ordem e isso também era uma demanda dos ambientalistas e setores progressistas do Congresso norte-americano na negociação para alcançar um acordo de livre comércio com os Estados

(9) Declaração disponível em: <http://www.aidesep.org.pe/index.php?codnota=733> Acesso em: 10.12.2009.

(10) Informação disponível em: <http://elcomercio.pe/noticia/301657/simon-acuerdo-pedir-derogacion-l-10901064-no-derrota-gobierno> Acesso em: 8.10.2009. 
Unidos”(11). Ele reconheceu, no entanto, que não falou com os líderes das comunidades nativas, para informar o real propósito dos decretos legislativos promulgados pelo executivo.

\section{Conclusões}

O capítulo sobre investimentos do TLC Peru-EUA, na medida em que abrange praticamente todos os setores da economia, poderia gerar no futuro uma série de litígios entre o Estado peruano e as empresas estadunidenses. Por privilegiar mais os interesses dos investidores, poderia ter efeitos negativos significativos sobre a condução das atividades da mineração, da exploração dos recursos naturais, na medida em que se protegem os interesses das empresas, ignorando os danos ambientais que estas geram.

O capítulo referente ao meio ambiente não protege as normativas ambientais frente ao mecanismo investidor-Estado. Mas ainda vemos a primazia dos interesses econômicos sobre o meio ambiente, como estão estabelecidas no capítulo sobre investimentos, as vantagens que terão os grupos de investidores frente ao meio ambiente. Por isso, cabe-nos perguntar: Será que TLC contribuirá eficazmente para o desenvolvimento sustentável nacional e ao benefício de toda a população as concessões feitas pelo Peru e as outorgadas pelos Estados Unidos ao Peru? Os precedentes exemplificados no âmbito do NAFTA já nos indicam que as preocupações ambientais são insignificantes frente aos interesses dos investidores estrangeiros, o comércio está acima da proteção ao meio ambiente.

Contrariamente às leis ambientais dos EUA, que controlam suas empresas poluidoras, por intermédio da Agência de Proteção Ambiental (Environmental Protection Agency), as leis peruanas sobre proteção ambiental existente foram deliberadamente concebidas, durante o governo de Fujimori na década de 1990 para serem fracos e proporcionar facilidades e garantias para os investidores estrangeiros em diversos setores. Estas promoções do investimento estrangeiro foram desenvolvidas com uma visão parcial, focado apenas em destacar os seus benefícios e vantagens econômicas para o Peru, mas carece de visão crítica e realista sobre os custos inevitáveis que também produzem. $\mathrm{O}$ subterfúgio usado é “atrair investimentos”; pouca atenção é dada à proteção do meio ambiente ou à saúde da sociedade peruana.

Estas deficiências de legislação ambiental no Peru foram demonstradas pelo número significativo de Decretos Legislativos promulgados pelo Presidente Alan Garcia, que visavam facilitar o acesso e a utilização dos recursos naturais. O TLC Peru-EUA seguirá gerando conflitos sociais como aconteceram desde a sua assinatura em 2005, que causou enormes mobilizações, especialmente entre os camponeses que eram os mais prejudicados pela eliminação de tarifas e proteções comerciais. Os conflitos sociais no Peru encontram-se latentes, principalmente pela diferença de visão do governo, por estar baseada na

(11) Informação disponível em: <http://elcomercio.pe/noticia/302117/presidente-garcia-reconocio-error-gobierno-al-no-consultarl-representantes-nativos $>$ Acesso em: 8.10.2009. 
lógica de comércio e de mercadoria frente ao qual a população reclama uma maior sensibilidade por parte das multinacionais poluidoras para com o meio ambiente.

\section{REFERÊNCIAS BibLIOGRÁFICAS}

ALMEIDA, T. Luciana; DUTRA, H. Paula; D’ANCONA Mauro. Comércio e meio ambiente. Economía Política Internacional: Análise Estratégica, n. 1, abr./jun. 2004.

BARANDIARÁN, G. Alberto. Análisis de la institucionalidad ambiental en los decretos legislativos de la implementación del TLC Perú - EEUU. Peru: Red Peruana por una Globalización con Equidad RedGE, 2008.

BID. Banco Interamericano de Desarrollo. Comercio y medio ambiente en Latinoamérica y el Caribe: prioridades y retos, 2005.

CELLI JUNIOR, Umberto. Teoria geral da integração: em busca de um modelo alternativo. In: MERCADANTE, Araminta de Azevedo; CELLI J. Umberto; ROCHA A. Leandro (coords.). Blocos econômicos e integração na América Latina, África e Ásia. Curitiba: Juruá, 2006.

CMMAD. Comissão Mundial de Meio Ambiente e Desenvolvimento. Nosso futuro comum. 2. ed. Rio de Janeiro, 1991.

ECHAVE, Víctor. La desregulación de la inversión extranjera en los TLCs y sus posibles efectos en la actividad minera. Lima: Corporación, 2006.

FAIRLIE, R. Alan; QUEIJA, S. Sandra; RASMUSSEN, A. Milagros. Tratado de libre comercio PerúEEUU: un balance crítico. Lima, 2006.

IISD. The International Institute for Sustainable Development. NAFTA's chapter 11 and the environment: addressing the impacts of the investor-state process on the environment. Canadá: IISD, 1999.

MENDOZA, N. Armando. TLC: blindando la inversión extranjera, tratamiento de las inversiones en el tratado de libre comercio y acuerdo de asociación comunidad Andina - Unión Europea CAN-UE. Lima: Centro Peruano de Estudios Sociales, 2008.

MORÓN, Eduardo et al. Tratado de libre comercio con los Estados Unidos: una oportunidad para crecer sostenidamente. Lima: Centro de Investigación de Universidad del Pacífico, 2005.

OECD. Organisation for Economic Co-operation and Development. Relationships between international investment agreements. OECD Trade and Environment Working Paper, 2004.

. Update on environment and regional trade agreements: developments in 2007. OECD Trade and Environment Working Paper, 2008.

PERU. Ministerio de Comercio Exterior y Turismo. TLC Perú-Estados Unidos: nociones claves. Peru: Ministerio de Comercio Exterior y Turismo, 2005.

PUBLIC CITIZEN. Public Citizen's Global Trade Watch. NAFTA's threat to sovereignty and democracy: the record of NAFTA chapter 11 investor-state cases 1994-2005, feb. 2005.

UNEP. United Nations Environment Programme. The use of economic instruments in environmental policy: opportunities and challenges. Geneva: UNEP, 2004. 